\title{
Time to stop blaming communism in Hungary
}

Restrictive funding criteria put young researchers at a disadvantage in many countries.

Sir - Your News Feature "Dreaming on the Danube" (Nature 427, 94-95; 2004) is right to emphasize the unused intellectual potential in Hungary but it gives a flawed image of Hungarian science overall.

First, the tendency to equate Hungary with its capital Budapest is always annoying. Although Budapest is home to about $20 \%$ of the Hungarian population for historical reasons, most Hungarian students do not study in Budapest and most Hungarian researchers do not work there.

I am a 30-year-old chemist working at the University of Debrecen in eastern Hungary. In my discipline, the international reputations of the research communities at three Hungarian universities (Debrecen, Szeged and Veszprém) are at least as good as, if not better than, that of their counterpart in Budapest. It is not accidental that the only Hungarian-born Nobel laureate who did his award-winning work in Hungary, Albert Szent-Györgyi, was a faculty member in Szeged.

Second, I think it is unhelpful to refer to the Hungarian language as "notoriously complex". Its internal logic is certainly very different from that of European languages, but this does not make it more complex. Hungarian is a language in which there is only one past, one present and one future tense for verbs.

Finally, I disagree that the brain-drain problem has anything to do with Sovietera thinking and the 'old guard'. I agree that the biggest obstacle to young Hungarian talent is the way in which research funding is distributed, but this problem is not unique to Hungary. Whenever grant recipients are primarily selected using criteria based on previous merit, such as the number of publications, it makes it difficult for young professionals to develop independent research.

Hungary has had two conservative and harshly anti-communist governments since 1990 and this system got their blessings as well. Blaming the old communist era for everything bad is a political game that has very little credibility now.

\section{Gábor Lente}

Department of Inorganic and Analytical Chemistry, University of Debrecen, 4010 Debrecen,

POB 21, Hungary

\section{Hungary: basic science needs European support}

Sir - Your News Feature "Dreaming on the Danube" (Nature 427, 94-95; 2004) painted a grim picture of Hungarian science, reflecting the frustration of young scientists with the funding system.

Having returned to Hungary in 1995 and established a laboratory with mostly foreign support, I agree that without this it is almost impossible for young scientists to return and establish independent research. But the real problem is the serious underfunding of research, especially basic research, which affects scientists of all ages.

In my opinion, Hungarian science should be discussed in its context within the European Union (EU), which could play a much greater role in revitalizing science in a country with a record of producing high-impact research for low cost.

In 2003, the average Hungarian Scientific Research Fund (OTKA) grant was roughly US\$10,000, minus $20 \%$ for value-added tax. In my experience, it takes at least ten times more to establish a competitive life-sciences research laboratory in Hungary. Fortunately, many foreign grants offer funding in this range for scientists under 35 who want to return to Hungary, but Hungarian science cannot rely for ever on the generosity of foreign charities. The question is: in a small country with a low gross domestic product (GDP), where will the money come from?

When I returned to Hungary, I hoped that this help would come eventually from the EU. But the EU has indirectly made matters worse, because the modest increase in Hungarian science funding has been used to emulate EU Framework programmes in supporting applied research, ignoring the needs of basic science and distributing disproportionately large funds to a lucky few. This approach is particularly problematic for a small country, which has its main strengths as your "Eastern promise" Editorial points out - " not in technology development, where existing policy has its focus, but in basic research" (Nature 426, 369; 2003).

The same Editorial mentioned that the European Commission is finally starting to recognize the importance of the "untapped scientific potential" of newly joining countries for the competitiveness of the EU.

Currently, support for basic research is left to the member countries in the EU, not all of which can afford it. To allow fair competition for EU money in both applied and basic research, specific funds should be established to support basic science in new EU member countries whose per capita GDPs are well below the European average.

Private organizations in Europe and overseas already support basic science in Hungary. In my view, if the EU is serious about expanding the European research area, it must do more than simply drain talent away from the new member countries. The cost of such investment would be minimal, because $0.25 \%$ of the EU's annual $€ 178$-billion (US\$227-billion) expenditure on research and development would create a fund ten times bigger than OTKA, and the EU could guarantee that the system would be fair and merit-based.
Then we could start working for Europe instead of dreaming about it.

László Hunyady

Department of Physiology, Semmelweis University, 1088 Budapest, Puskin u. 9, Hungary

\section{Let's hope there's a good year on the cards}

Sir — Yet another Christmas and New Year have gone by without a card from The Journal of This or Trends in That, in either mail box, real or electronic.

A little odd in a communicationsconscious society, no? Perhaps I didn't provide any 'expert' reviewing last year after all. Of course, I may just have unfashionable views of the festive season, coming as I do from the last century when people believed in Santa Claus and Mickey Mouse.

Come on, Editors, be a trifle old-fashioned for once, even if you do resort to e-mail.

Best wishes for what will surely be another glorious year in science.

Simon Wain-Hobson

Molecular Retrovirology Unit, Department of Virology, Institut Pasteur, 25 rue du Docteur Roux, 75724 Paris Cedex 15, France

Nature sent each of our reviewers for 2003 a copy of the last issue of the year with a letter of thanks - Editor, Correspondence.

\section{correspondence}

Contributions to Correspondence may be submitted to corres@nature.com. They should be no longer than 500 words, and ideally shorter. 